\title{
EFETIVIDADE DOS DIREITOS E DOS DEVERES COM OBJETO DIFUSO
}

EFFECTIVENESS OF RIGHTS AND DUTIES WITH DIFFUSE OBJECTS

EFECTIVIDAD DE LOS DERECHOS Y DE LOS DEBERES CON OBJETO

DIFUSO

Rodrigo Coimbra ${ }^{1}$

1 Doutor em Direito pela PUCRS. Mestre em Direito pela UFRGS. Professor da Graduação da Faculdade de Direito e do Programa de Pós-Graduação em Direito da UNISINOS, São Leopoldo, Estado do Rio Grande do Sul, Brasil. Advogado. E-mail: rodrigo.coimbra@terra.com.br 
Resumo: O presente ensaio propõe o estudo dos direitos e dos deveres com objeto difuso a partir da aplicação do Direito objetivo, de modo a valorizar preponderantemente o ponto de vista da sociedade na sua totalidade. Pensar a problemática dos direitos difusos mediante a aplicação do Direito objetivo é uma forma de superar o individualismo que marca a cultura jurídica desde o direito romano e atrapalha a compreensão desse fenômeno tão importante, de modo a lhes conferir maior efetividade.

Palavras-chave: Direitos com objeto difuso. Perspectiva objetiva. Direito objetivo. Direito subjetivo. Direitos fundamentais.

Abstract: This paper proposes studies rights and duties with diffuse objects, by applying objective law, in order to promote mainly the point of view of society as a whole. Thinking of the issue of diffuse rights through the application of objective Law is a way to overcome the individualism that has marked the legal culture since the time of Roman law, and hinders the understanding of this important phenomenon.

Keywords: Rights with diffuse objects. Objective perspective. Objective law. Subjective law. Fundamental rights.

Resumen: El presente ensayo propone el estudio de los derechos y de los deberes con objeto difuso a partir de la aplicación del Derecho objetivo, de modo que se valorice preponderantemente el punto de vista de la sociedad en su totalidad. Pensar la problemática de los derechos difusos mediante la aplicación del Derecho objetivo es una forma de superar el individualismo que marca la cultura jurídica desde el Derecho Romano y confunde la comprensión de ese fenómeno tan importante, otorgándole mayor efectividad.

Palabras clave: Derechos con objeto difuso. Perspectiva objetiva. Derecho objetivo. Derecho subjetivo. Derechos fundamentales. 


\section{INTRODUÇÃO}

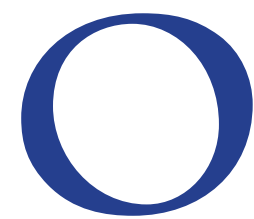

presente ensaio apresenta proposta para conferir maior efetividade aos direitos e aos deveres com objeto difuso, a partir da aplicação do Direito objetivo e da perspectiva objetiva dos direitos fundamentais.

A pesquisa se justifica em face da importância dos direitos e deveres com objeto difuso na sociedade atual e propõe um método que prescinde da noção de direito subjetivo para a sua concretização.

O objetivo geral é demonstrar que a baixa efetividade dos direitos e deveres com objeto difuso se deve à utilização do modelo dos direitos individuais, centrado na noção de direito subjetivo para os direitos com objeto difuso. Dentre os objetivos específicos, destaca-se a análise da denominação do fenômeno a partir da doutrina de Pontes de Miranda acerca do objeto do Direito. Não é objetivo do presente trabalho abordar os direitos individuais homogêneos e os direitos coletivos stricto sensu.

O problema de estudo investigado é se a noção de direito subjetivo, nuclear para os direitos individuais (homogêneos ou não), se aplica ou não aos direitos e deveres com objeto difuso.

A hipótese defendida é de que aos direitos com objeto difuso não se deve utilizar da noção de direito subjetivo, auferindo sua concretização a partir da aplicação e, por vezes, criação do Direito objetivo.

O estudo está dividido, em seu desenvolvimento, em três partes, iniciando pela localização da noção de direito subjetivo, passando pela delimitação e denominação do fenômeno dos direitos com objeto difuso, chegando a sua aplicação mediante a aplicação do Direito objetivo, alinhada a perspectiva objetiva dos direitos fundamentais.

Como método científico de abordagem do assunto, é utilizado o método dedutivo, partindo de princípios gerais para chegar a conclusões particulares. A abordagem da pesquisa se dá pelo modelo qualitativo, na medida em que se buscará o entendimento do fenômeno em seu próprio contexto. 


\section{LOCALIZAÇÃO DA NOÇÃO DE DIREITO SUBJETIVO}

A noção de direito subjetivo, que passa a ser, na época do modelo de Estado Liberal, uma das mais altas expressões da autonomia dos sujeitos, com um casamento perfeito com o individualismo², é uma fundamental categoria jurídica para a construção e a sedimentação tanto do direito privado como do direito processual, com raízes importantes na Idade Média.

Segundo Villey, "a pré-história da idéia de direito subjetivo" surge com Ockam 4 (1285-1347), provavelmente, o primeiro a edificar teoria sobre o direito subjetivo, por ocasião da querela que surge entre a congregação dos franciscanos e o papado na Idade Média. Os franciscanos têm como regra o voto de pobreza, porém, como sua ordem religiosa se estende rapidamente e muitos de seus seguidores são possuidores de bens importantes, o Papa João XXII teme que essa ordem religiosa fique sem os bens de seus seguidores. Diante disso, o Papa João XXII, baseado na opinião de ilustres especialistas em direito canônico e romano da época, habilmente, cria uma solução para o conflito: as propriedades dos franciscanos permanecem na disposição da congregação (usufruto - ius utendi e ius fruendi), mas o domínio de tais bens pertence à Santa Sé. Então, o monge franciscano Ockam intervém na discussão a favor dos franciscanos, sustentando que o direito (ius) não é o bem de que desfrutamos, mas o poder que se tem sobre esse bem. ${ }^{5}$

2 Conforme Irti, nessa época, "o valor originário e fundamental é constituído pelo indivíduo, por sua capacidade individual, por sua liberdade de escolher suas próprias metas, seus objetivos, assumindo sozinho o risco do sucesso e do fracasso". Em torno do indivíduo são construídas todas as relações sociais (IRTI, Natalino. L'età della decodificazioni. 4. ed. Milano: Giuffrè, 1999, p. 21).

3 VILLEY, Michel. A formação do pensamento jurídico moderno. Tradução de Claudia Berliner. São Paulo: Martins Fontes, 2005, p. 261-288.

4 Ockam, também grafado Ockham, é considerado nominalista, juntamente com Duns Scotus (1266-1308), entre outros. A corrente nominalista, em síntese, "opõe-se aos realistas na questão dos universais. Para o nominalismo, os universais (os termos universais, aquilo que a gramática normativa designava por substantivos comuns e alguns casos são abstratos) são conceitos, mas não têm uma existência real. São de uma existência nominal, como instrumentos do pensamento" (LOPES, José Reinaldo de Lima. O Direito na história. São Paulo: Max Limonad, 2000, p. 165).

5 Marchettoni, criticando Villey, diz que não é correto sustentar que Ockam foi individualista no seu pensamento político e muito menos em relação a sua teoria de direito subjetivo. O autor sustenta, em síntese, que a teoria ockaniana do direito não é individualista, mas comunitária, visto que, para Ockam, a ênfase na liberdade individual nunca é separada do 
É a primeira separação da expressão direito, segundo Villey ${ }^{6}$, pois, até então, tem-se presente o significado original e unívoco de "ius" formulado pelos jurisconsultos romanos Ulpiano e Paulo, que, em comum, concebem o direito como a arte do justo e do bom, tomando-se por base a natureza das coisas. ${ }^{7}$ Em outras palavras, a palavra "ius" está conectada a "iustitia", que indica conformidade com o direito, tanto no sentido objetivo como no subjetivo. ${ }^{8}$ Nesse ponto, Marchettoni ${ }^{9}$ concorda com Villey, no sentido de que, no direito romano, a noção de direito subjetivo é ignorada.

A partir dessa concepção, o direito deixa de ser um "bem", para se tornar o "poder que se tem sobre os bens", ou o "poder de impô-lo à observância dos demais". Villey ${ }^{10}$ considera isso uma autêntica revolução copernicana verificada na ciência jurídica. Nesse sentido, são esclarecedoras as passagens a seguir proferidas por Ovídio Baptista: ${ }^{11}$

[...] Subjetiva-se, portanto, o conceito, ao mesmo tempo em que se elimina dele qualquer relação com a moral, posto que, agora, a questão

sentido de comunidade (MARCHETTONI, Leonardo. Ockham e L'origine dei diritti soggettivvi. In: Quaderni Fiorentini: per la storia del pensiero giuridico moderno. Milano: Guiffrè, n. 37, p. 21-66, em especial, p. 64, jan. 2008); Lopes diz que Ockam é individualista, no entanto ele se refere a comunidades, esclarecendo que toda sua metafísica e seu universo jurídico são dos indivíduos e coisas singulares (LOPES, José Reinaldo de Lima. O Direito na história. São Paulo: Max Limonad, 2000, p. 172).

6 VILLEY, Michel. A formação do pensamento jurídico moderno. Tradução de Claudia Berliner. São Paulo: Martins Fontes, 2005, p. 266; "Forse, così, è anticipata la teoria moderna della soggetivazione del diritto oggetivo", conforme SFORZA, Widar Cesarini. Diritto soggettivo. In: Enciclopedia del diritto. Milano: Guiffrè, 1964, v. XII, p. 672.

7 Para Ulpiano "ius" significa: "[...] ut eleganter Celsus definit, ius est ars boni et aequm". E para Paulo: "[...] quod semper aequum ac bonum est, ius dicitur, ut est ius naturale". Essas definições contêm em comum o "iustum et aequm". "Di ius si era consolidato il significato oggetivo, sicché equivaleva a iussum ed era quase sinônimo di lex, ma tavolta, se riferito a una persona privata, esprimera il suum di questa". [...] "A ius si connete iustitia, parola indicante talora la conformità al ius in senso tanto oggettivo che sogettivo", conforme SFORZA, Widar Cesarini. Diritto soggettivo. In: Enciclopedia del diritto. Milano: Guiffrè, 1964, v. XII, p. 670.

8 "A ius si connete iustitia, parola indicante talora la conformità al ius in senso tanto oggettivo che sogettivo", conforme SFORZA, Widar Cesarini. Diritto soggettivo. In: Enciclopedia del diritto. Milano: Guiffrè, 1964, v. XII, p. 670.

9 MARCHETTONI, Leonardo. Ockham e L'origine dei diritti soggettivvi. In: Quaderni Fiorentini: per la storia del pensiero giuridico moderno. Milano: Guiffrè, n. 37, p. 21-66, em especial, p. 21-22, jan.2008.

10 VILLEY, Michel. A formação do pensamento jurídico moderno. Tradução de Claudia Berliner. São Paulo: Martins Fontes, 2005, p. 266.

11 BAPTISTA DA SILVA, Ovídio Araújo. Jurisdição e execução na tradição romano-canônica. 3. ed. Rio de Janeiro: Forense, 2007, 120-121. 
do merecimento formaliza-se, passando a decorrer necessariamente da lei, enquanto norma estatal. [...] Vê-se da concepção do padre franciscano como a relação entre sujeito e o respectivo bem que lhe é atribuído pela norma deixa de ter relevância conceitual, para priorizarse o poder de impor aos demais a observância do próprio direito, ou, como ele diz 'o poder de apropriar-se' dos bens que the sejam concedidos. [...]

[...] São perfeitamente visíveis, na filosofia do monge franciscano do século XIV, as raízes do voluntarismo, que depois dominou a filosofia do século XVII [...]. (Grifos do autor)

A ideia de direito associada a poder, e não ao justo, surgida no século XIV, com Ockam, tem importantes reflexos nas doutrinas jurídicas posteriores, principalmente a partir do movimento pandectista alemão do século XIX, que tem por preocupação doutrinal o estudo do desenvolvimento do direito subjetivo. ${ }^{12}$

Assim, a noção de direito subjetivo tem assentamento no jusnaturalismo em atenção à consideração do Direito em função do indivíduo. A experiência cultural do Renascimento produz um pensamento filosófico de caráter individualista que valoriza a liberdade humana. Trata-se de uma exigência do jusnaturalismo, a fim de garantir as prerrogativas fundamentais do homem em confronto com os poderes do soberano. Nesse contexto, o direito subjetivo ganha o centro do sistema jurídico como expressão da livre personalidade humana e sua personalidade em face da vontade do soberano. ${ }^{13}$

Nesse quadro, Savigny ${ }^{14}$, na linha voluntarista da sua época (1779-1861), diz:

Si contemplamos los hechos jurídicos que en la vida real nos rodean y dominan, nos aparece en primer lugar el poder correspondiente

12 RIBEIRO, Darci Guimarães. La pretensión procesal y la tutela judicial efectiva: hacia uma Teoría Procesal del Derecho. Barcelona: Bosch, 2004, p. 39.

13 GAVIÃO FILHO, Anizio Pires. A atualidade da teoria de Georg Jellinek como estrutura para o sistema de posições jurídicas fundamentais. Revista da Faculdade de Direito da Fundação

Escola Superior do Ministério Público - RS. n. 1. Porto Alegre: FMP, 2007, p. 34-72, p. 42.

14 SAVIGNY, KIRCHMANN, ZITELMANN, KANTOROWICZ. La ciência del Derecho. Buenos Aires: Losada, 1949, p. 29. Nessa mesma linha, Savigny já havia escrito em outra obra: "Considerado en la vida real, abrazando y penetrando por todos lados nuestros ser, nos aparece como un poder del individuo. Em los limites de este poder, reina la voluntad del individuo, y reina con el consentimiento de todos. A tal poder ó facultad lo llamamos nosotros 'derecho', y algunos derecho en su sentido subjetivo" (SAVIGNY, M. F. C. de. Sistema de derecho romano actual. 2. ed. Madrid: Centro Editorial de Góngora. [s.d.], v. 1, p. 5). 
a la persona particular: una esfera en la cual su voluntad reina con nuestro consentimento. Denominamos este poder un derecho de esta persona, en el sentido de faculdade. Algunos lo llaman derecho en sentido subjetivo.

Esse trecho da obra de Savigny evidencia noções importantes sobre a sua concepção de direito subjetivo: a) o direito subjetivo é um poder; b) o direito subjetivo é um poder do indivíduo; c) o direito subjetivo é um poder da vontade do indivíduo. Essa concepção é seguida e consagrada por Windscheid, conforme será tratado a seguir.

Esclarece Wieacker ${ }^{15}$ que a definição de Savigny de direito subjetivo está fundamentada no conceito kantiano ${ }^{16}$ do Direito como espaço da liberdade que possa coexistir com a liberdade dos outros e na autonomia daí decorrente: a existência autônoma do Direito, que não deve forçar a eticidade autônoma da pessoa, mas, antes, deve possibilitá-la.

A definição de Savigny demonstra, com rara clareza, a histórica vinculação do direito subjetivo ao individualismo e ao voluntarismo (vontade individual), características fundamentais para a problematização levantada no presente trabalho.

Bodin de Moraes $^{17}$ diz que a imponente elaboração de Savigny se dá, fundamentalmente, por meio do conceito de "direito subjetivo individual" (grifouse), isto é: "do atribuir-se à vontade individual um domínio dentro do qual ela reina independentemente de qualquer vontade estranha". Segundo essa concepção, prossegue a autora ${ }^{18}$, "os direitos subjetivos delimitavam os amplos domínios reservados à autonomia privada, garantindo assim a liberdade individual por meio de autorizações subjetivas, provenientes, exclusivamente, do próprio poder da vontade do indivíduo".

15 WIEACKER, Franz. História do direito privado moderno. 2. ed. Lisboa: Fundação Calouste Gulbenkian, 1993, p. 440 e 453.

16 Para Kant (1724-1804), "o direito estrito se apóia no princípio de lhe ser possível usar constrangimento externo capaz de coexistir com a liberdade de todos de acordo com as leis universais.". [...] "Direito e competência de empregar coerção, portanto, significam uma e única coisa" (KANT, Immanuel. A metafísica dos costumes. São Paulo: EDIPRO, 2003, p. 78).

17 MORAES, Maria Celina Bodin de. Constituição e Direito Civil: Tendências. Direito, Estado e Sociedade. n. 15, p. 95-113, em especial, p. 103, ago.-dez. 1999.

18 MORAES, Maria Celina Bodin de. Constituição e Direito Civil: Tendências. Direito, Estado e Sociedade. n. 15, p. 95-113, em especial, p. 103, ago.-dez. 1999. 
Destaca Ovídio Baptista ${ }^{19}$ que o direito subjetivo, nessa época, "deve ser entendido como poder da vontade exercido contra alguém individualmente, já que seria impensável a existência de um direito subjetivo, assim definido, pressupondo a supremacia de vontade do respectivo titular, exercido contra a comunidade jurídica inteira".

Windscheid (1817-1892), maior representante da teoria voluntarista ${ }^{20}$ e da escola rigorosamente conceitual e sistemática da pandectística alemã21, define o direito em sentido subjetivo (direito subjetivo) como faculdade, que se manifesta em duplo sentido, como se constata a seguir.

a) O ordenamento jurídico (direito em sentido objetivo - Direito objetivo ${ }^{22}$ ) estabelece certas condutas (ação ou omissão) e deixa à livre disposição (autonomia da vontade) de aquele em cujo benefício foi emitido o preceito (titular do direito) fazer valer ou não (faculdade) o Direito objetivo preceituado. A vontade do titular do direito é decisória para a efetividade do mandado emitido pelo ordenamento jurídico. O ordenamento jurídico desprende-se do mandado por ele emitido em favor do titular, transformando seu próprio mandado em mandado do titular do direito. O "direito" (objetivo) transforma-se em "seu direito" (subjetivo). ${ }^{23}$ É o que se passa a classificar como direitos subjetivos a uma prestação ou direitos subjetivos prestacionais.

b) O ordenamento jurídico atribui ao facultado a autonomia da vontade

19 BAPTISTA DA SILVA, Ovídio Araújo. Jurisdição e execução na tradição romano-canônica. 3. ed. Rio de Janeiro: Forense, 2007, 120-121.

20 Para Windscheid, "a tarefa do direito privado é traçar os limites dos campos de vontade dos indivíduos que vivem em comum, de definir em que medida a vontade de cada indivíduo deve ser decisiva para os indivíduos com os quais se enfrenta. Esta finalidade o ordenamento jurídico privado alcança por meio de proposições jurídicas imperativas e proibitivas" (Tradução de livre de WINDSCHEID, Bernard. Diritto dele pandette. Prima Traduzione Italiana. Volume Primo. Parte Prima. Torino: Unione Tipografico - Editrice Torinese, 1902, p. 80).

21 Da pandectista resultou uma suma do direito privado (como antes nos grandes comentários do jurista Ulpiano ou da Glossa Ordinária), cuja fama geral levou até os países mais distantes a influência e a vigência da pandectista. Na Alemanha, a obra de Windscheid levou ao seu chamamento à primeira comissão para o Código Civil (BGB), onde teve uma influência dominante, conforme WIEACKER, Franz. História do direito privado moderno. 2.ed. Lisboa: Fundação Calouste Gulbenkian, 1993, p. 510.

22 Opta-se, neste trabalho, pelo emprego das expressões "Direito objetivo" e "direito subjetivo". Todavia, nas transcrições de autores serão observadas as terminologias por eles utilizadas.

23 WINDSCHEID, Bernard. Diritto dele pandette. Prima Traduzione Italiana. Volume Primo. Parte Prima. Torino: Unione Tipografico - Editrice Torinese, 1902, p. 169-170. 
(vontade decisória) não para a realização, mas para a formação (existência) de direitos estabelecidos pelo próprio Direito objetivo. ${ }^{24}$ Trata-se, segundo o autor, de outro significado da palavra direito (subjetivo). É o que se passa a classificar como direitos subjetivos potestativos ou formativos ${ }^{25}$.

Conclui Windscheid ${ }^{26}$ que ambas as espécies de direito subjetivo compreendem a sua famosa definição, que consagra a chamada teoria da vontade: o direito (subjetivo) é um poder de vontade reconhecido pela ordem jurídica. Nas edições posteriores da sua obra, em resposta a objeções que sofre, notadamente de Jhering, Windscheid ${ }^{27}$ esclarece que a "vontade" é do ordenamento jurídico, não do titular do direito.

Jhering (1818-1892) ${ }^{28}$, mediante ampla argumentação contestando a "teoria da vontade" do contemporâneo Windscheid, sustenta que o direito (subjetivo) não é o adorno, o objeto da vontade, mas a sua condição: "os direitos não são o fim da vontade, ainda que lhe sirvam de meio". Se a vontade fosse o objeto do direito, como teriam direito as pessoas sem vontade, como os incapazes, questiona o autor, sustentando que os direitos não existem para realizar a ideia da vontade

24 WINDSCHEID, Bernard. Diritto dele pandette. Prima Traduzione Italiana. Volume Primo. Parte Prima. Torino: Unione Tipografico - Editrice Torinese, 1902, p. 170.

25 Por volta de 1896, Zitelmann, havia, pela primeira vez na doutrina, mencionado uma categoria especial de direitos, que denominou de direitos potestativos. Segundo Zitelmann, na teoria geral, os direitos subjetivos se classificariam em duas categorias fundamentais: os direitos aos quais corresponde uma prestação, que se exercem e cumprem-se mediante uma prestação da outra parte; e direitos que se exercitam independentemente de qualquer prestação da parte contrária, do sujeito passivo da relação jurídica (LACERDA, Galeno. Teoria geral do processo. Rio Janeiro: Forense, 2008, p. 220-221).

26 "Diritto è una podestà o signoria della voluntà impartita dall'ordine giuridico" (WINDSCHEID, Bernard. Diritto dele pandette. Prima Traduzione Italiana. Volume Primo. Parte Prima. Torino: Unione Tipografico - Editrice Torinese, 1902, p. 170).

27 "Volontà dello Stato", conforme SFORZA, Widar Cesarini. Diritto soggettivo. In: Enciclopedia del diritto. Milano: Guiffrè, 1964, v. XII, p. 685. Ovídio Baptista, a partir da assimilação do conceito de direito subjetivo como poder da vontade conferido, consagrado por Windscheid, diz que "a relação jurídica deverá, necessariamente, traduzir-se numa relação obrigacional entre sujeitos de direito, nunca numa relação do titular do direito com a coisa que lhe pertence", provocando "uma profunda inversão conceitual, se compararmos a visão moderna com a concepção clássica do fenômeno jurídico": o direito, em seu sentido original, não se confundia, absolutamente, com a lei, e, menos ainda, como hoje se passou a concebê-lo, com o poder que o titular terá para impor sua vontade contra outrem. Essa concepção moderna de direito, como direito subjetivo, corresponde a uma autêntica "revolução copernicana", como a provocada por Kant, na mesma linha da revolução operada por ele na filosofia moderna (BAPTISTA DA SILVA, Ovídio Araújo. Jurisdição e execução na tradição romano-canônica. 3. ed. Rio de Janeiro: Forense, 2007, 117-118).

28 JHERING, Rudolf Von. Espíritu del Derecho Romano. 2. ed. Madrid: Revista de Occidente, 1962 , p. 443 e 445. 
jurídica abstrata, mas para garantir os interesses da vida, ajudar a satisfazer as suas necessidades e realizar seus fins. Para o autor, a utilidade (não a vontade) é a substância do direito (elemento substancial) que deve ser somada ao meio para esse fim, que é a proteção do Direito objetivo por meio da possibilidade de ajuizamento de ação judicial em caso de violação do direito (elemento formal). A partir daí, Jhering expõe seu conceito clássico de direito subjetivo, consagrando a chamada teoria do interesse: "os direitos são interesses juridicamente protegidos".

Jellinek (1851-1911) ${ }^{29}$, visando traçar seu conceito de direito subjetivo público, acaba consagrando a chamada "teoria mista", que combina o poder de vontade com a finalidade de proteger os interesses dos indivíduos. Para o autor, o direito subjetivo (subjetividade jurídica) se expressa por meio do reconhecimento, pelo Estado, da posição do indivíduo como pessoa, como membro do Estado e dotado de direitos individuais perante a esfera pública, pois essa concessão do Estado possibilita ao indivíduo (poder de vontade) colocar em movimento o sistema jurídico para realizar um interesse, mediante o reconhecimento do ordenamento jurídico (Direito objetivo). Para essa concepção, o direito subjetivo é, portanto, um poder da vontade humana que recai sobre um bem ou um interesse e que o ordenamento jurídico reconhece e protege.

Em suma, essas são as três teorias mais difundidas a respeito da definição do direito subjetivo e sua relação com o Direito objetivo. Existem várias teorias sobre o direito subjetivo e, no presente trabalho, opta-se pelo estudo da chamada pré-história do direito subjetivo (Ockam) e das teorias clássicas de Windscheid, Jhering e Jellinek, além de mais duas que se elegem como relevantes, como as de Kelsen e de Pontes de Miranda.

Kelsen ${ }^{30}$ (1881-1973), contestando detalhadamente as três teorias mais tradicionais sobre direito subjetivo (teoria da vontade, de Windscheid; teoria do

29 JELLINEK, Georg. La dottrina generale del diritto dello Stato. Traduzione italiana sulla terza edizione tedesca. Milano: Giuffrè, 1949, p. 23 e 30.

30 KELSEN, Hans. Problemas Capitales de la Teoria Jurídica del Estado: desarrolados con base em la doctrina de la proposición jurídica. México: Porruá, 1987, p. 493-578 (Tradução de da segunda edição em alemão, de 1923), combinado com KELSEN, Hans. Teoria geral do Direito e do Estado. Tradução de Luís Carlos Borges. 2. ed. São Paulo: Martins Fontes, 1992, p. 82-83 (publicada originalmente com título: General Theory of Law and State, em 1945). 
interesse, de Jhering; teoria mista, de Jellinek), inova ao romper com a noção da doutrina do Direito Natural segundo a qual o direito "subjetivo" e o dever possuem existências independentes do ordenamento jurídico, tendo em vista que, para essa doutrina, as normas jurídicas se limitam a proteger ou garantir direitos subjetivos considerados lógica e temporalmente anteriores ao Direito objetivo ${ }^{31}$.

Kelsen ${ }^{32}$ altera a relação de precedência de direito (subjetivo) $\rightarrow$ dever para dever $\rightarrow$ direito (subjetivo), a partir da concepção de que a base de tudo é o Direito objetivo (a norma), salientando, todavia, que "um direito é mais do que o correlativo de um dever". De acordo com a teoria Kelseniana, o direito subjetivo é o poder jurídico eventualmente (não necessariamente ${ }^{33}$ ) concedido pelo Direito objetivo, mediante uma ação, para que o Estado (por meio do poder judiciário) aplique a sanção (determinada pelo próprio Direito objetivo) àquele que não cumpriu um determinado dever imposto pela norma ${ }^{34}$.

O Direito de um é o dever de outro, considerado do ponto de vista daquele frente ao qual está este dever. Fala-se, por isso, de um 'Direito' no sentido subjetivo da palavra. Direito no sentido subjetivo pode, por sua vez, - no âmbito de uma ordem jurídica - ter uma significação especificamente técnica. $O$ 'Direito' de um não é, pois, mero reflexo do dever de um outro. Este Direito subjetivo só existe, pois, se a sanção

31 "No começo, existiam apenas direitos subjetivos - em especial o protótipo de todos os direitos, o direito a propriedade (obtida por ocupação) - e apenas num estágio posterior o Direito objetivo como ordem do Estado foi acrescentado com o propósito de sancionar e proteger os direitos que, independentemente dessa ordem, haviam passado a existir. Esta idéia é desenvolvida com mais clareza na teoria da Escola Histórica, que foi decisivamente influenciada, não apenas pelo positivismo jurídico do último século, mas também pela jurisprudência moderna dos países de língua inglesa" (KELSEN, Hans. Teoria geral das normas. Tradução de José Florentino Duarte. Porto Alegre: Fabris, 1986, p. 82-83).

32 KELSEN, Hans. Teoria geral das normas. Tradução de José Florentino Duarte. Porto Alegre: Fabris, 1986, p. 175, combinado com KELSEN, Hans. Teoria geral do Direito e do Estado. Tradução de Luís Carlos Borges. 2. ed. São Paulo: Martins Fontes, 1992, p. 81-82.

33 Para Kelsen, a essência do Direito está em impor condutas determinadas, por meio do estabelecimento de deveres. O estabelecimento de direitos no sentido subjetivo é uma opção do Direito objetivo. Nesse contexto: a) podem existir deveres sem direitos "subjetivos", mas não pode haver direitos "subjetivos" sem deveres dos outros; b) a previsão de direitos subjetivos "é uma função possível, não uma função necessária de um ordenamento jurídico positivo" (KELSEN, Hans. Teoria geral das normas. Tradução de José Florentino Duarte. Porto Alegre: Fabris, 1986, p. 175).

34 KELSEN, Hans. Teoria geral das normas. Tradução de José Florentino Duarte. Porto Alegre: Fabris, 1986, p. 174-175. Segundo Mario Losano, recorrendo à concepção de dever jurídico, Kelsen abandona a concepção de direito subjetivo herdada da doutrina romanista e considera-o fundamento da pretensão jurídica, excluindo toda consideração psico-sociológica (LOSANO, Mario G. Teoría pura del Derecho: evolución y puntos cruciales. Bogotá: Editorial Temis, 1992, p. 25). 
que deve ser aplicada pelo órgão aplicador do Direito, especialmente pelo tribunal, no caso de não-cumprimento de dever, tiver de se realizar apenas a requerimento do sujeito lesado em seu interesse pelo não cumprimento do dever; de modo que a fixação da norma individual, com a qual se ordena a sanção, por uma ação dirigida a tal fim - demanda, queixa -, é solicitada por aquele frente a quem existe não cumprido - dever. Então esse bem, à sua disposição, o Direito que estatui o dever, o Direito é seu Direito. ${ }^{35}$ (Grifos do autor)

No Brasil, destaca-se o posicionamento de Pontes de Miranda (1892-1979) ${ }^{36}$, o qual, depois de advertir que o direito subjetivo é uma abstração à que sutilmente se chega após o exame da eficácia dos fatos jurídicos criadores de direitos, sustenta que a regra jurídica é objetiva e incide nos fatos, assim, o suporte fático torna-se fato jurídico: "o que, para alguém, determinadamente, dessa ocorrência emana, de vantajoso, é direito, já aqui subjetivo, porque se observa o lado desse alguém, que é o titular dele". O autor prescreve não ser possível se conceber o direito subjetivo, quer histórica, quer logicamente, sem o Direito objetivo, de modo que, incidindo a regra jurídica, o direito subjetivo é "o que resulta do lado positivo da incidência", portanto, "há nele um pode", esclarecendo, todavia, que o direito subjetivo não é uma faculdade, "contém a faculdade". Em suma, para Pontes de Miranda, direito subjetivo "é a vantagem que veio a alguém, com a incidência da regra jurídica em algum suporte fáctico". ${ }^{37}$

Para Pontes de Miranda, o direito subjetivo é todo direito de que a regra objetiva dota os sujeitos de direito, "conferindo-Ihes projeção própria, atuação voluntária ou não". ${ }^{38}$ Essa projeção própria é a "individualização" da posição jurídica, o reconhecimento de que "alguém, a quem o direito objetivo atribui

35 KELSEN, Hans. Teoria geral das normas. Tradução de José Florentino Duarte. Porto Alegre: Fabris, 1986, p. 174. Em outra obra, o autor trata o "direito subjetivo" como sinônimo de "pretensão", traduzido na exigência da conduta devida (dever), quando tal dever não esteja sendo cumprido tal como determinado pelo direito objetivo (norma), em Teoria pura do direito. Tradução de João Baptista Machado. 6. ed. São Paulo: Martins Fontes, 1999, p. 142.

36 PONTES DE MIRANDA, Francisco Cavalcanti. Tratado de direito privado. Rio de Janeiro: Borsoi, 1955, t. 5, p. 231-233.

37 PONTES DE MIRANDA, Francisco Cavalcanti. Tratado de direito privado. Rio de Janeiro: Borsoi, 1955, t. 5, p. 226. Alexy refere-se ao direito subjetivo como "posição jurídica" e propõe a divisão e a pluralidade dos direitos subjetivos (direito a algo, liberdades; competências), conforme ALEXY, Robert. Teoria de los derechos fundamentales. Madrid: Centro de Estudios Constitucionales, 1997, p. 177-178.

38 PONTES DE MIRANDA, Francisco Cavalcanti. Tratado da ação rescisória. 3. ed. Rio de Janeiro: Borsoi, 1957, p. 5-6. 
ou reconhece tal posição, pode invocá-lo, não como sujeito ativo, e sim como sujeito ativo em que o direito se precisou". ${ }^{39}$ (Grifos do autor)

Em face da contextualização e das teorias do direito subjetivo expostas, procura-se demonstrar que o arraigamento histórico e cultural dos direitos individuais, por muito tempo hegemônico, está ligado, substancialmente, ao individualismo, ao voluntarismo, ao patrimonialismo e à concepção de direito subjetivo da época, salientando que, embora as teorias clássicas de direitos subjetivos sejam diferentes - e tais diferenças sejam importantes -, todas são pensadas tendo em vista apenas a tutela de direitos aos indivíduos (no máximo, para pessoas jurídicas ${ }^{40}$ ).

O arraigamento histórico e cultural dos direitos individuais é um dos principais óbices para a aceitação e a adequada tutela (material e processual) dos direitos transindividuais, que provocaram e continuam provocando uma profunda transformação, a qual precisa acompanhar a tendência evolutiva do mundo contemporâneo e dar respostas mais efetivas à sociedade.

\section{DELIMITAÇÃO E DENOMINAÇÃO DO FENÔMENO DOS DIREITOS COM OBJETO DIFUSO}

Éimportante sublinhar que as diferenças conceituais entre os direitos individuais homogêneos e os direitos transindividuais - direitos coletivos stricto sensu e direitos difusos - repercutem em um necessário tratamento diferenciado.

Impõe-se esse tratamento bifurcado, pois, de um lado, em se tratando de direitos individuais homogêneos, tem-se, em verdade, um feixe de direitos individuais, reunidos de forma coletiva para fins processuais (tutela coletiva de direitos, na expressão de Zavascki ${ }^{41}$ ), de modo que cada indivíduo é titular de um direito subjetivo, que pode ser perseguido de forma individual ou coletiva, tendo o 39 PONTES DE MIRANDA, Francisco Cavalcanti. Tratado da ação rescisória. 3. ed. Rio de Janeiro: Borsoi, 1957, p. 10.

40 WINDSCHEID, Bernard. Diritto dele pandette. Prima Traduzione Italiana. Volume Primo. Parte Prima. Torino: Unione Tipografico - Editrice Torinese, 1902, p. 209-212.

41 ZAVASCKI, Teori Albino. Processo coletivo: tutela de direitos coletivos e tutela coletiva de direitos. 4. ed. São Paulo: Editora Revista dos Tribunais, 2009, p. 145. 
ordenamento jurídico viabilizado a tutela coletiva apenas para permitir tratamento uniforme das pretensões e para diminuir o número de ações individuais sobre a mesma matéria. Os direitos individuais (homogêneos ou não) são pensados sob a luz da perspectiva subjetiva.

De outro lado, os direitos coletivos stricto sensu e os direitos difusos (tutela de direitos coletivos, na expressão de Zavascki ${ }^{42}$ ) têm por titular uma coletividade e possuem objeto que transcende os indivíduos, não sendo passíveis de apropriação individual. Nesse sentido, o Supremo Tribunal Federal $^{43}$ pronunciou que o direito ao ambiente ecologicamente equilibrado tem "titularidade coletiva e caráter transindividual", sendo atribuído "não ao indivíduo identificado em sua singularidade, mas, num sentido mais abrangente, à própria coletividade social".

Entende-se que a melhor denominação para o fenômeno dos "chamados direitos difusos" é "direito com objeto difuso" 44 , pois não é o direito que é difuso, mas é o seu objeto que pode ser difuso, entre outras classificações.

De acordo com Pontes de Miranda45, o objeto de direito "é algum bem da vida que pode ser elemento do suporte fáctico de alguma regra jurídica, de cuja incidência emane fato jurídico, produto de direito", esclarecendo o autor que objeto do direito é "o que pode ser atingido pela eficácia do fato jurídico: nos direitos reais, é o substrato mesmo deles, e diz-se coisa; nos direitos de crédito, é a promessa; nos outros direitos, é a vida, a liberdade, o nome, a honra, a própria pessoa, ou a pessoa de outrem, ou outro direito". (destaque do original).

Na classe difusa, os objetos do direito podem ser: o patrimônio público ou de entidade de que o Estado participe; a moralidade administrativa; o meio ambiente; o patrimônio histórico e cultural; as relações de consumo; as relações de trabalho;

42 ZAVASCKI, Teori Albino. Processo coletivo: tutela de direitos coletivos e tutela coletiva de direitos. 4. ed. São Paulo: Editora Revista dos Tribunais, 2009, p. 53.

43 SUPREMO TRIBUNAL FEDERAL. Tribunal Pleno, ADI n. 3.540-1/DF, Relator Min. Celso de Mello, DJ 01/09/2005.

44 Não obstante entenda-se que "direito com objeto difuso" é a expressão mais adequada para o fenômeno, também se utiliza no presente trabalho a expressão "direito difuso" por ser a mais usada na doutrina e na jurisprudência pátrias.

45 PONTES DE MIRANDA, Franscisco Cavalcanti. Tratado de direito privado. 3. ed. Rio de Janeiro: Borsoi, 1970, t. 2, p. 9 e 16. 
os bens e os direitos de valor artístico, estético, turístico e paisagístico; a ordem econômica; a ordem urbanística, entre outros.

Adverte Pontes de Miranda 46 ser "da máxima relevância evitar-se confusão entre objeto dos atos jurídicos (e até dos fatos jurídicos stricto sensu) e objeto de direito". Exemplifica o autor que o objeto do negócio jurídico bilateral de compra e venda não é a coisa, mas a prestação prometida (a promessa).

O objeto do direito pode ser considerado no presente, no passado e no futuro. Segundo a lição pontiana, o objeto de direito "ou é considerado no futuro, como bem da vida que pode ser atingido pela eficácia jurídica, ou no presente e no passado, como bem da vida que foi ou está sendo atingido pela eficácia jurídica". ${ }^{47}$ Essa observação é importante para os direitos com objeto difuso, pois muito se fala nas futuras gerações no que tange ao direito ao meio ambiente, por exemplo.

Nesse particular, observa Tesheiner ${ }^{48}$ que "as gerações futuras guiar-se-ão por seus próprios critérios, independentemente do que dizemos agora. Se vierem a respeitar nossos decretos de prescrição, será simplesmente por entenderem que essa é a melhor solução. Poderão ou não respeitar as decisões passadas, assim como nós, as de nossos antepassados".

Nos direitos com objeto difuso, o objeto é considerado como um só, "de natureza indivisível", segundo a legislação brasileira ${ }^{49}$, gerando "a conseqüente comunhão de destinos dos respectivos titulares, de modo tal que a satisfação de um só implicaria, por força, a satisfação de todos, assim como a lesão de um só constitui lesão à inteira comunidade", conforme destaca Barbosa Moreira. ${ }^{50}$ Essa destinação "unitária" dos direitos com objeto difuso (indivisibilidade) é uma de suas características diferenciadas. A respeito dessa característica do objeto,

46 PONTES DE MIRANDA, Franscisco Cavalcanti. Tratado de direito privado. 3. ed. Rio de Janeiro: Borsoi, 1970, t. 2, p. 9.

47 PONTES DE MIRANDA, Franscisco Cavalcanti. Tratado de direito privado. 3. ed. Rio de Janeiro: Borsoi, 1970, t. 2, p. 17.

48 Artigo inédito, gentilmente cedido pelo autor.

49 Conforme o conceito disposto no art. 81, I, da Lei 8.078/90. In: BRASIL. Lei 8.078, de 11 de setembro de 1990. Dispõe sobre a proteção do consumidor e dá outras providências. Coletânea de Legislação e Jurisprudência, Brasília. Lex: Legislação Federal e Marginália.

50 MOREIRA, José Carlos Barbosa. Os temas fundamentais do direito brasileiro nos anos 80: direito processual civil. Temas de direito processual. 4. série. São Paulo: Saraiva, 1989, p. 8. 
averba Pontes de Miranda: "o objeto é considerado como um só, se é utilizado como um só bem jurídico (utilização unitária)". 51

Observe-se que só se pode falar em objeto de direito no plano da eficácia. Conforme destaca Pontes de Miranda52, "no mundo jurídico, para os três planos não há a mesma sorte para os objetos, inclusive as coisas: no plano da existência jurídica, não há falar-se em objetos de direitos; nem no plano da validade; só no plano da eficácia, em que os direitos, as pretensões, as ações e as exceções se produzem, é que se pode falar em objetos de direito e, pois, em coisas". Em outros termos, o meio ambiente ou o patrimônio histórico só é objeto de direito a partir do momento em que há direito, pretensões, ações ou exceções em relação a ele, o que se dá no plano da eficácia.

Observe-se que alguns direitos com objeto difuso são denominados pelo próprio ordenamento jurídico como "bens", como ocorre na Lei da ação civil pública (Lei 7.347/85), ao tutelar "bens e direitos de valor artístico, estético, histórico, turístico e paisagístico" (art. $1^{\circ}$, III).

De acordo com Pontes de Miranda, o conceito de "bem", no Código Civil (ainda que o autor estivesse se referindo ao Código Civil de 1916, essa parte conceitual sobre os bens foi mantida pelo Código Civil de 2002), "é aproximativamente o de objeto de direito; mais amplo, pois, que o de coisa".

Consoante a lição de Orlando Gomes"53, a noção jurídica de bem "compreende toda utilidade, física ou ideal, que possa incidir na faculdade de agir do sujeito. Abrange as coisas propriamente ditas, suscetíveis de apreciação pecuniária, e as que não comportam essa avaliação, as que são materiais ou não". Para o autor, o objeto dos direitos "são os bens e as prestações", portanto, os bens são um dos objetos de direito, sendo que "tomada no sentido mais claro, a palavra bem confunde-se com o objeto dos direitos".

51 PONTES DE MIRANDA, Franscisco Cavalcanti. Tratado de direito privado. 3. ed. Rio de Janeiro: Borsoi, 1970, t. 2, p. 9.

52 PONTES DE MIRANDA, Franscisco Cavalcanti. Tratado de direito privado. 3. ed. Rio de Janeiro: Borsoi, 1970, t. 2, p. 17. Sobre os planos do mundo jurídico, ver também MELLO, Marcos Bernardes de. Teoria do fato jurídico: plano da existência. 8. ed. São Paulo: Saraiva, 1998 , p. $79-85$.

53 GOMES, Orlando. Introdução ao direito civil. 18. ed. Rio de Janeiro: Forense, 2001, p. 199. 
Nesse quadro, tem-se importante a delimitação anteriormente realizada e a utilização da denominação da expressão "direitos com objeto difuso" como a mais apropriada para explicar o fenômeno.

\section{APLICAÇÃO DO DIREITO OBJETIVO E VALORIZAÇÃO DA PERSPECTIVA OBJETIVA DOS DIREITOS FUNDAMENTAIS}

Para explicar a tutela jurisdicional dos direitos com objeto difuso, como a do meio ambiente, por exemplo, não se deve lançar mão da noção de direitos subjetivos - noção que, nesse particular, apenas turva a clareza do pensamento -, podendo-se chegar à concretização pela aplicação do Direito objetivo.

Nesse sentido, Tesheiner ${ }^{54}$ afirma que "nas ações relativas aos chamados 'direitos difusos', o juiz aplica, e às vezes também cria Direito objetivo". O autor justifica arguindo que há extensões do Direito objetivo que não geram direitos subjetivos, como no caso dos interesses difusos, e exemplifica: "não se precisa da idéia de 'direito ao ar puro', para explicar a proibição de poluir".

Destacando a importância da realização do Direito objetivo, Pontes de Miranda ${ }^{55}$ reafirma que "a finalidade preponderante, hoje, do processo é a realizar o Direito, o direito objetivo, e não só, menos ainda precipuamente, os direitos subjetivos". E o processo, segundo Pontes de Miranda ${ }^{56}$, manifestará sua importância, justamente quando não houver a realização espontânea (automática) do Direito objetivo: "o processo não é mais do que o corretivo da imperfeita realização automática do direito objetivo".

54 TESHEINER, José Maria Rosa. Revista eletrônica sobre os chamados? direitos difusos?.

Processos Coletivos. Porto Alegre, v. 3, n. 4, out.-dez. 2012. Disponível em: <http:// www.processoscoletivos.net/ pcoletiv/component/jcomments/feed/com_content/724>. Acesso em: 24 out. 2012.

55 PONTES DE MIRANDA, Francisco Cavalcanti. Comentários ao Código de Processo Civil. Rio de Janeiro: Forense, 1999, t. 1, p. 77. A importância da concretização do ordenamento jurídico objetivo também é destacada por Molinaro e Milhoranza: "Jurisdição, no seu núcleo duro, é o poder do Estado de dizer o direito, o direito, o direito que é, ademais de concretizar o ordenamento jurídico objetivo" (MOLINARO, Carlos Alberto; MILHORANZA, Mariângela Guerreiro. Processo e direitos fundamentais - brevíssimos apontamentos. Revista Brasileira de Direito Processual. Belo Horizonte: Fórum, n. 79, p. 127-145, em especial p. 139, jul.-set. 2012).

56 PONTES DE MIRANDA, Francisco Cavalcanti. Comentários ao Código de Processo Civil. Rio de Janeiro: Forense, 2001, t. 1, p. 78. 
Há criação ou aplicação do Direito objetivo - inexistindo direito subjetivo nesses casos -, quando o Judiciário, por exemplo: a) determina a um Município (Tubarão - SC) a elaboração, no prazo de um ano, de projeto executivo de sistema de esgoto sanitário e a implementação, em dois anos, de rede de esgotos que sirva a $50 \%$ da população, devendo chegar à cobertura total no prazo de cinco anos; b) determina que empresas de ônibus regularizem o serviço de quatro linhas de ônibus (no Rio de Janeiro); c) determina que hospital restabeleça atendimento (em Duque de Caxias - RJ); d) obriga fabricante (Unilever) a informar, nas embalagens dos produtos são que comercializados, dados essenciais, como prazo de validade e medidas a serem adotadas no caso de ingestão indevida, de forma que possibilite a fácil leitura e compreensão pelo consumidor; e) impede a cobrança de ponto de extra de TV por assinatura; f) mantém proibição de extração de areia nas margens do Rio Paraná. ${ }^{57}$

Os direitos difusos devem ser pensados mediante a aplicação do Direito objetivo e a partir da perspectiva objetiva dos direitos fundamentais. A perspectiva objetiva dos direitos e deveres fundamentais possui "função autônoma" na concretização do Direito, mediante o "reconhecimento de efeitos jurídicos autônomos", consoante explica Sarlet ${ }^{58}$ : "cuida-se aqui de apontar para os desdobramentos da perspectiva objetiva dos direitos fundamentais na qualidade de efeitos potencialmente autônomos, no sentido de não necessariamente atrelados aos direitos fundamentais consagradores de direitos subjetivos".

No âmbito do direito ambiental - típico direito com objeto difuso -, Carla Amado Gomes ${ }^{59}$ posiciona-se contrariamente ao reconhecimento subjetivo ao 57 Todos esses casos foram retirados de <http://www.processoscoletivos.net/ponto-e-contraponto $>$. Acesso em: 30 out. 2012.

58 SARLET, Ingo Wolfgang. A eficácia dos direitos fundamentais: uma teoria geral dos direitos fundamentais na perspectiva constitucional. 10. ed. Porto Alegre: Livraria do Advogado, 2011, p. 141, 147 e 228.

59 "[...] entendemos ser o direito ao ambiente uma fórmula vazia de significado jurídico em virtude da impossibilidade de determinação de um conteúdo para tal posição jurídica, a construção baseia-se na $2^{\mathrm{a}}$ parte do $\mathrm{n}^{\circ} 1$ do artigo $66^{\circ}$ da CRP, que autonomiza o dever fundamental de protecção do ambiente, densificável a partir da definição de prestações concretas relativamente a bens naturais determinados. Esta nossa construção pressupõe, no entanto, a existência de deveres (de protecção do ambiente) por causa do exercício de direitos (de circulação, de propriedade, de investigação científica). Ou seja, sobretudo na presença de obrigações de facere, o raciocínio implica que o dever de protecção do ambiente - cuja configuração concreta depende da(s) actividade(s) desenvolvida(s) pelo sujeito -, emerja como contrapartida do exercício de determinados direitos. Não significa 
meio ambiente, sustentando que ele deve ser pensado sob uma perspectiva exclusivamente objetiva.

Canotilho ${ }^{60}$, examinando o ordenamento jurídico português, entende que o direito ao ambiente é um direito subjetivo. Demonstrando que a compreensão dessa questão depende do ordenamento jurídico de cada país, o autor lusitano refere que o direito ao ambiente não é um direito subjetivo no direito constitucional espanhol, "porque não assegura, só por si, um direito de acção em tribunal".

Em que pese o aprofundamento acerca dessa querela fuja dos limites do presente trabalho, partilha-se do entendimento de Amado Gomes e, ampliando-o, entende-se que os direitos com objeto difuso devem ser pensados sob a perspectiva objetiva e não são passíveis de subjetivação.

Trata-se de "direitos assubjetivos" ou "Direito objetivo não subjetivado", conforme as expressões de Pontes de Miranda ${ }^{61}$, segundo o qual "não há direitos sem sujeitos. Nem todos os direitos são subjetivos. Interêsses são protegidos sem que a ordem jurídica crie direitos subjetivos. Muitas vêzes, os mais eficazmente protegidos, ou, até, os mais enèrgicamente assegurados, são interesses que não permitem a invocação do direito subjetivo. São esferas não menos importantes, da função só preventiva ou só repressiva do Estado". ${ }^{62}$ Essa lição de Pontes de Miranda, quando ele trata do tema "sujeito e subjetivo", é importante para os direitos com objeto difuso, pois a ordem jurídica protege-os, Ihes dá eficácia, mas sem lhes conferir direitos subjetivos.

Em clara alusão aos interesses transindividuais, Pontes de Miranda ${ }^{63}$ afirma

isto que o dever de protecção do ambiente seja correlativo de um direito com o mesmo objecto - já vimos que essa orientação é de rejeitar. Trata-se, isso sim, de verificar uma ligação incindível entre uma responsabilidade individual de uso racional de um bem de uso colectivo e a pretensão jurídica de levar a cabo determinadas actividades que, pela sua incidência ambiental, requerem cuidados mais ou menos acrescidos" (GOMES, Carla Amado. Risco e modificação do acto autorizativo concretizador de deveres de protecção do ambiente. Lisboa: Faculdade de Direito de Lisboa, 2007, p. 129).

60 CANOTILHO, José Joaquim Gomes. O direito ao ambiente como direito subjectivo. In: Estudos sobre direitos fundamentais. Coimbra: Coimbra, 2004, p. 186-187.

61 PONTES DE MIRANDA, Francisco Cavalcanti. Tratado da ação rescisória. 3. ed. Rio de Janeiro: Borsoi, 1957, p. 8 e 12.

62 PONTES DE MIRANDA, Francisco Cavalcanti. Tratado da ação rescisória. 3. ed. Rio de Janeiro: Borsoi, 1957, p. 8.

63 PONTES DE MIRANDA, Franscisco Cavalcanti. Tratado de direito privado. Rio de Janeiro: Borsoi, 1955, t. 5, p. 228. 
que há casos em que, "sem terem os particulares direitos subjetivos, a relevância do interêsse geral sugeriu que a esses se atribuísse ação dita popular (actio popularis)". Conclui o autor, na sequência do seu raciocínio: "destarte, há interesses protegidos, sem que se chegue, tecnicamente, à subjetivação" (destaque do original).

Na linha de não subjetivação dos direitos coletivos, Clóvis do Couto e Silva refere que "há um problema semelhante em matéria de tutela de interesses coletivos. Estes interesses não podem ser qualificados como direitos subjetivos". ${ }^{64}$

Nessa trilha, Tesheiner" ${ }^{65}$ afirma que "pelo menos quanto aos direitos difusos, é fácil ver-se que não se trata de direitos subjetivos".

Tratando da correlação entre Direito e dever, Pontes de Miranda ${ }^{66}$ diz que "o dever de atender à regra jurídica não é correlativo dos direitos que a regra jurídica cria ou transforma", ou seja, que o Direito objetivo pode optar por não criar direitos subjetivos, destacando que "o direito objetivo pode ser perfeito sem existir tal garantia"67 (direito subjetivo).

Ajuda a compreender a matéria o exemplo dado por Pontes de Miranda:

A regra que manda abrir a tantas horas os jardins públicos e fechálos a certo momento da noite, ou conservá-los sempre abertos para que todos êles passem, possam sentar-se, descansar, é direito nãosubjetivo. Os passantes, os freqüentadores e os que dêles se servem para ler, trabalhar, como as mulheres que aproveitam a sombra das árvores para coser ou vigiar crianças, não têm direito subjetivo a isso, porque nem todos os direitos e posições jurídicas que se gozam são direitos subjetivos. ${ }^{68}$ ("destaque do original").

64 COUTO E SILVA, Clóvis Veríssimo do. O conceito de dano no Direito brasileiro e comparado. In: 0 Direito Privado brasileiro na visão de Clóvis do Couto e Silva. FRADERA, Vera Jacob. (Org.). Porto Alegre: Livraria do Advogado, 1997, p. 217-235, em especial, p. 222. Esse artigo foi publicado originalmente na Revista dos Tribunais, ano 80, v. 667, mai1991.

65 TESHEINER, José Maria Rosa. Jurisdição e direito objetivo. Justiça do Trabalho. n. 325, p. 31, jan. 2011.

66 PONTES DE MIRANDA, Francisco Cavalcanti. Tratado da ação rescisória. 3. ed. Rio de Janeiro: Borsoi, 1957, p. 12.

67 PONTES DE MIRANDA, Francisco Cavalcanti. Tratado da ação rescisória. 3. ed. Rio de Janeiro: Borsoi, 1957, p. 9.

68 PONTES DE MIRANDA, Francisco Cavalcanti. Tratado da ação rescisória. 3. ed. Rio de Janeiro: Borsoi, 1957, p. 6. 
Frise-se o ponto: "nem todos os direitos e posições jurídicas que se gozam são direitos subjetivos" e isso não significa que não sejam passíveis de realização. Note-se que Pontes de Miranda grifou em itálico a expressão "que se gozam", evidenciando a possibilidade de fruição de certos direitos sem haver direito subjetivo. Esse exemplo de utilização dos parques públicos é tipicamente um interesse/direito difuso (ainda que o autor não tenha mencionado isso, pois não Ihe interessava essa abordagem).

O direito subjetivo, realmente, não é a única forma de gozar os direitos, nem a única posição jurídica subjetiva, não obstante seja hegemônica na nossa tradição jurídica.

\section{CONSIDERAÇÕES FINAIS}

A melhor denominação para o fenômeno dos "chamados direitos difusos" é "direito com objeto difuso", pois não é o direito que é difuso, mas é o seu objeto que pode ser difuso, entre outras classificações.

Os direitos e os deveres com objeto difuso devem ser estudados a partir da Constituição e dos direitos e dos deveres fundamentais e vinculam-se à perspectiva ou à dimensão objetiva dos direitos fundamentais, que os considera não apenas sob o ponto de vista da pessoa individual e sua posição perante o Estado, mas também valoriza e reforça o ponto de vista da sociedade, da comunidade na sua totalidade, quando se tratar de valores e fins que transcendem a esfera do indivíduo tanto em direitos como em deveres.

Para explicar a tutela jurisdicional dos direitos com objeto difuso não se deve lançar mão da noção de direitos subjetivos (muito importante para a consolidação e para a efetivação dos direitos individuais, homogêneos ou não), chegando-se à concretização pela aplicação e, por vezes, criação de Direito objetivo.

A adequada tutela de direitos com objeto difuso exige repensar inúmeros institutos do direito material e processual clássicos, porquanto vários deles foram imaginados para operar - e somente conseguem operar adequadamente - no 
plano individual, tendo reduzida ou nenhuma função no plano difuso.

De fato, o direito subjetivo foi criado para operar e opera de forma hegemônica no plano dos direitos individuais. Dentro dessa noção de individualidade que reflete a cultura e a sociedade do modelo de Estado liberal, o termo direito - no sentido subjetivo - somente é utilizado nas hipóteses em que a sua titularidade pertence a um sujeito determinado e há um objeto delimitado.

A presente proposta não desconsidera que as pessoas são o fim último do Direito, pelo contrário, apresenta um método que prescinde da noção de direito subjetivo, visando conferir maior efetividade a essa classe de direitos de tamanha repercussão para a sociedade.

Pensar a problemática dos direitos difusos a partir da aplicação do Direito objetivo é uma forma de superar o individualismo que marca a cultura jurídica desde o direito romano e atrapalha a compreensão desse significativo fenômeno.

\section{REFERÊNCIAS}

ALEXY, Robert. Teoria de los derechos fundamentales. Madrid: Centro de Estudios Constitucionales, 1997.

BAPTISTA DA SILVA, Ovídio Araújo. Jurisdição e execução na tradição romano-canônica. 3.ed. Rio de Janeiro: Forense, 2007.

CANOTILHO, José Joaquim Gomes. O direito ao ambiente como direito subjectivo. In: Estudos sobre direitos fundamentais. Coimbra: Coimbra, 2004.

COUTO E SILVA, Clóvis Veríssimo do. O conceito de dano no Direito brasileiro e comparado. In: O Direito Privado brasileiro na visão de Clóvis do Couto e Silva. FRADERA, Vera Jacob. (Org.). Porto Alegre: Livraria do Advogado, 1997, p. 217-235.

GAVIÃO FILHO, Anizio Pires. A atualidade da teoria de Georg Jellinek como estrutura para o sistema de posições jurídicas fundamentais. Revista da Faculdade de Direito da Fundação Escola Superior do Ministério Público - RS. n. 1. Porto Alegre: FMP, p. 34-72, 2007.

GOMES, Carla Amado. Risco e modificação do acto autorizativo concretizador de deveres de protecção do ambiente. Lisboa: Faculdade de Direito de Lisboa, 2007. 
GOMES, Orlando. Introdução ao direito civil. 18. ed. Rio de Janeiro: Forense, 2001.

IRTI, Natalino. L'età della decodificazioni. 4. ed. Milano: Giuffrè, 1999.

JELLINEK, Georg. La dottrina generale del diritto dello Stato. Traduzione italiana sulla terza edizione tedesca. Milano: Giuffrè, 1949.

JHERING, Rudolf Von. Espíritu del Derecho Romano. 2. ed. Madrid: Revista de Occidente, 1962.

KANT, Immanuel. A metafísica dos costumes. São Paulo: EDIPRO, 2003.

KELSEN, Hans. Teoria pura do direito. Tradução de João Baptista Machado. 6.ed. São Paulo: Martins Fontes, 1999.

Problemas Capitales de la Teoria Jurídica del Estado: desarrolados con base em la doctrina de la proposición jurídica. México: Porruá, 1987.

Teoria geral das normas. Tradução de José Florentino Duarte. Porto Alegre: Fabris, 1986.

Teoria geral do Direito e do Estado. Tradução de Luís Carlos Borges. 2. ed. São Paulo: Martins Fontes, 1992.

LACERDA, Galeno. Teoria geral do processo. Rio Janeiro: Forense, 2008.

LOPES, José Reinaldo de Lima. O Direito na história. São Paulo: Max Limonad, 2000.

LOSANO, Mario G. Teoría pura del Derecho: evolución y puntos cruciales. Bogotá: Editorial Temis, 1992.

MARCHETTONI, Leonardo. Ockham e L'origine dei diritti soggettivvi. In: Quaderni Fiorentini: per la storia del pensiero giuridico moderno. Milano: Guiffrè, n. 37, p. 21-66, jan.2008.

MELLO, Marcos Bernardes de. Teoria do fato jurídico: plano da existência. 8.ed. São Paulo: Saraiva, 1998.

MOLINARO, Carlos Alberto; MILHORANZA, Mariângela Guerreiro. Processo e direitos fundamentais - brevíssimos apontamentos. Revista Brasileira de Direito Processual. Belo Horizonte: Fórum, n. 79, p. 127-145, jul.-set. 2012.

MORAES, Maria Celina Bodin de. Constituição e Direito Civil: Tendências. Direito, Estado e Sociedade. n. 15, p. 95-113, ago.-dez. 1999. 
MOREIRA, José Carlos Barbosa. Os temas fundamentais do direito brasileiro nos anos 80: direito processual civil. Temas de direito processual. 4. série. São Paulo: Saraiva, 1989.

PONTES DE MIRANDA, Francisco Cavalcanti. Comentários ao Código de Processo Civil. Rio de Janeiro: Forense, 1999, t. 1.

Tratado da ação rescisória. 3. ed. Rio de Janeiro: Borsoi, 1957.

Tratado de direito privado. 3. ed. Rio de Janeiro: Borsoi, 1970, t. 2.

Tratado de direito privado. 4. ed. São Paulo: Revista dos Tribunais, 1974, t. 1.

Tratado de direito privado. Rio de Janeiro: Borsoi, 1955, t. 5.

RIBEIRO, Darci Guimarães. La pretensión procesal y la tutela judicial efectiva: hacia uma Teoría Procesal del Derecho. Barcelona: Bosch, 2004.

SARLET, Ingo Wolfgang. A eficácia dos direitos fundamentais: uma teoria geral dos direitos fundamentais na perspectiva constitucional. 10. ed. Porto Alegre: Livraria do Advogado, 2011.

SAVIGNY, KIRCHMANN, ZITELMANN, KANTOROWICZ. La ciência del Derecho. Buenos Aires: Losada, 1949.

SAVIGNY, M. F. C. de. Sistema de derecho romano actual. 2. ed. Madrid: Centro Editorial de Góngora. [s.d.], v. 1.

SFORZA, Widar Cesarini. Diritto soggettivo. In: Enciclopedia del diritto. Milano: Guiffrè, 1964, v. XII.

TESHEINER, José Maria Rosa. Jurisdição e direito objetivo. Justiça do Trabalho. n. 325, p. 31, jan. 2011.

. Revista eletrônica sobre os chamados? direitos difusos?. Processos Coletivos. Porto Alegre, v. 3, n. 4, out.-dez. 2012. Disponível em: <http://www.processoscoletivos.net/ pcoletiv/ component/jcomments/feed/com_content/724>. Acesso em: 24 out. 2012.

VILLEY, Michel. A formação do pensamento jurídico moderno. Tradução de Claudia Berliner. São Paulo: Martins Fontes, 2005.

WIEACKER, Franz. História do direito privado moderno. 2. ed. Lisboa: Fundação Calouste Gulbenkian, 1993. 
WINDSCHEID, Bernard. Diritto dele pandette. Prima Traduzione Italiana. Volume Primo. Parte Prima. Torino: Unione Tipografico - Editrice Torinese, 1902.

ZAVASCKI, Teori Albino. Processo coletivo: tutela de direitos coletivos e tutela coletiva de direitos. 4. ed. São Paulo: Editora Revista dos Tribunais, 2009.

Recebido em: jul/2013

Aprovado: set/2014 